\title{
BUILDING RESILIENT COALITIONS: HEALTH AND MEDICAL RESPONSE THROUGH COVID-19 CONCURRENT EVENTS
}

\author{
LORI UPTON $^{1}$, ADAM LEE $^{1} \&$ MAGDALENA ANNA DENHAM ${ }^{2}$ \\ ${ }^{1}$ SouthEast Texas Regional Advisory Council, USA \\ ${ }^{2}$ Department of Security Studies, Sam Houston State University, USA
}

\begin{abstract}
This study examines the role of the non-profit organization SouthEast Regional Advisory Council (SETRAC) in capacity-building among healthcare institutions in the largest medical center in the world in the Houston, Texas region. Specifically, using conceptual resilience model accessed by organizations as they respond to crisis or disruption, we assess the linking dimension of SETRAC in healthcare delivery during COVID-19 concurrent disasters through supporting and coordinating services to healthcare institutions amid the pandemic. Specifically, the assessment comprises two critical events in the region concurrent to the COVID-19 pandemic - Hurricane Laura in fall 2020 and Winter Storm Uri in spring 2021. Our inquiry adopts the classical content analysis suitable for analyzing large textual data of 802 open-ended after-action report (AAR) surveys conducted among healthcare system entities in the region of which 403 collected post Hurricane Laura and 399 AARs collected after the Winter Storm Uri. Our findings center on discussion of three categories of capabilities: (a) established capabilities; (b) developing capabilities; and (c) unmet capabilities. The purpose of the study is to illuminate the role of a non-profit coalition in enhancing and sustaining a decentralized network of healthcare providers in the management of increasingly complex and compounded disasters and to identify best practices for coordination and collaboration across a range of concurrent hazards and threats.

Keywords: COVID-19 concurrent crises, healthcare coalitions, healthcare disaster management, SETRAC, resiliency, crisis communications, healthcare systems, Hurricane Laura, Winter Storm Uri.
\end{abstract}

\section{INTRODUCTION}

The COVID-19 pandemic constitutes a paradigm shift in the approach to hazards and threats especially within the traditional cycle of emergency management. Specifically, natural hazard-triggered crises or threat-triggered crises tend to be characterized by distinct geographic locations, have clearly defined duration, and tend to fall within specific phases of response and recovery activities. Meanwhile, the protracted nature of the pandemic and its persistence, as well as its global dispersement present unique challenges to emergency management and require adaptations beyond accepted norms and existing structures [1]. Consequently, in healthcare and public health sectors, systems have had to perform under longitudinal stress [2]. Moreover, it has been difficult to discern concrete phases of response and recovery because of inherent uncertainty of the pandemic crisis, potential multiple waves as well as emerging new strands of the virus such as the UK, New York, Brazil, and Indian variants [3], all making the trajectory of the disaster quite non-linear. Indeed, "Transitioning from pandemic response to recovery in a spiral fashion: there is a high probability of the second and even the third wave of a pandemic if there is no vaccine or immunization, each new wave pushing the disaster risk reduction cycle from the recovery back to response phase" $[1$, p. 3]. Concurrently, the pandemic has ushered second and third-order harms affecting many sectors of the economy and society [4]. Most critically, the temporal persistence of the pandemic has created an opportunity for multiple intersections with cyclical weather events such as storms, earthquakes, wildfires, or other concurrent or systemic crises thus 
compounding the complexity of required disaster management practices [2]. Markedly, meteorological hazards such as droughts or floods or geophysical hazards such as earthquakes occur commonly and cause disasters every year worldwide [5]. Admittedly, in 2020 more than 70 countries registered flood events coinciding with COVID-19 cases present in those countries [6]. The phenomenon of the overlap and compounding of one crisis with another has been referred to in research as concurrent crises [7] while others might refer to it as multi-hazard crises [8].

One of the earliest concurrent crises studied during COVID-19 was 21 March 2020, 5.3 Richter scale magnitude earthquake in the capital of Croatia, Zagreb [9]. The compounding disaster happened within the first month of COVID-19 response in the city causing structural damages to include critical hospital infrastructure. The affected zone comprised 199 health facility buildings, to include 42 healthcare centers, 115 hospitals and clinics, 20 health institutes and 22 pharmacies. Of those, 39 suffered moderate damage and eight were heavily damaged [10]. Consequently, hospital evacuations were necessary to include those from COVID-19 designated hospitals, which at that time provided care to 22 COVID-19 patients, the majority of whom were treated in the intensive care unit [9]. The earthquake response stressed already overextended healthcare workers, caregivers and other staff exposed to the infected and sick, placing them at a much higher risk. It is noteworthy that Croatia was under lockdown procedures at the time of the earthquake. Thus, mobilizing special damage assessment teams was difficult as many volunteer engineers living outside of Zagreb could not be mobilized for days [11]. Meanwhile dozens of residential homes were destroyed, and hundreds of individuals sought temporary housing. There were reports of 15,000 to 20,000 people moving out of the downtown area and a shelter created at a student dormitory housed approximately 500 displaced [10]. Even though the impact of the concurrent crisis was relatively localized and even though the authorities attempted to strictly enforce lockdown measures to prevent human social congregate behavior post disaster, infection rates within the incubation period after the earthquake revealed upward trends that could be attributed to temporary breakdown of social distancing practices [7]. Indeed researchers [10] concurred that in the initial hours post disaster hundreds of individuals were in the streets despite required lockdowns.

Crises concurrent to COVID 19 have been especially devastating to nations with rapid spread of COVID-19 such as Bangladesh because of (a) population density; (b) limited healthcare facilities; (c) sheltering camps housing more than a million refugees from Myanmar; and (d) migratory labor population traffic from COVID-19 affected countries; those factors contributed to the pandemic itself becoming a humanitarian crisis on an unprecedented scale [12]. Thus, the advent in May of 2020 of Cyclone Amphan, the most powerful cyclone in the region for two decades, represented in its timing, a threat to cyclone shelters that could become potential hotbeds of the spread of COVID-19. In Bangladesh cyclone shelters, community buildings, and schools conventionally used as evacuation centers during cyclonic activity, had at the time functioned as quarantine facilities and many served for quarantine processes of immigrant populations. The concurrent crises created a perfect storm of compatibility of two missions - that of sheltering vulnerable populations from the cyclone and that of protecting the public from COVID-19. According to research [3], international shelter space standards require $3.5 \mathrm{~m}^{2}$ per individual; however, social distancing elevates that space to about $6 \mathrm{~m}^{2}$ during a pandemic reducing overall sheltering capacity by $50 \%$. This reduces the capacity of any existing evacuation center to almost $50 \%$. Ultimately, in Bangladesh, rapid, ad hoc risk assessments were conducted and allowed for triaging shelters into half occupancy in areas of severe risk and full occupancy in those at a less serious risk of infection [13]. Overall, 12,078 cyclone shelters with 2.4 million evacuees 
were established in Bangladesh coastal areas affected by Amphan [14]. The unprecedented mobilization by humanitarian and governmental organizations admittedly limited deaths from the cyclone to 80 , thus achieving the first mission. This included sheltering "in the densely crowded camps in Cox' Bazar, which shelter some 900,000 Rohingya refugees" [15, p. 1]. However, COVID-19 cases spiked in Amphan-affected regions underscoring challenges of weighing and prioritizing risks from concurrent disasters [16]. Indeed, based on accounts of community-based women's organization in Bangladesh called Prerona and whose members were supporting cyclone shelters' efforts "maintaining physical distancing was a major challenge in a densely occupied shelter. There were around 100-120 people sheltered in 5-7 rooms. In one cyclone shelter around 15-20 people stayed in one room, with 4-5 families who knew each other very well not wanting to be separated" [14, para. 9].

Beyond emerging research on concurrent crises in international contexts, US researchers stress the need to study compound crises because "for a long time, researchers and policy makers often treated disasters "as though they were discrete events"' Peek said. "Our moment is obviously teaching us how important it is to think about people and systems when there are multiple disasters that are unfolding simultaneously" [17, para. 31]. Clearly, operational environments in contexts of multi-hazard scenarios are characterized by unique stressors that test the overall resiliency of response systems. For example, in context of COVID-19 and social distancing, intersecting hazards that necessitate implementation of evacuation procedures require adaptations from conventional models to dispersed evacuations or generation of alternative non-congregate sheltering arrangements such as hotels. Thus, because concurrent crises represent unique opportunities for researchers to study response systems pushed beyond their conventional capabilities and activities, the purpose of this study is to assess healthcare and public health system capabilities and challenges encountered during COVID-19 response at the intersection of two COVID-19 concurrent crises (fall 2020 and spring 2021) occurring in Texas and affecting the largest medical complex in the world. The Hurricane Laura that hit the US Gulf Coast in August 2020 was the strongest US storm on record in 2020, landing as category 4 with winds of $241 \mathrm{~km} / \mathrm{h}(150 \mathrm{mph})$ [18]. While its most catastrophic impact was recorded in Louisiana where Hurricane Laura's intensity was the strongest storm recorded since 1851, Texas counties of Jefferson, Orange, Hardin, Tyler, Jasper, and Newton suffered significant damages [19]; moreover, Hurricane Laura caused 186,000 power outages in the state [20] and prompted evacuations of at least half million residents in Texas and Louisiana before the landfall. For example, Galveston County, Texas ordered mandatory evacuations of low-lying areas [21]; after the storm at least 5,000 individuals were in Texas shelters [22]. Whereas hurricanes represent a cyclical occurrence in Texas, the second concurrent COVID-19 crisis, Winter Storm Uri in February 2021 brought catastrophic freezing temperatures not recorded in the state since 1899 [23]. Winter Storm Uri left approximately 10 million Texans without power for several days causing near collapse of the independent Texas power grid, mass relocations, people seeking shelter at warming stations, and catastrophic damages to residential utilities' infrastructure due to lack of winterization. The so called "ice-pocalypse" claimed lives of at least 111 people due to low temperatures or carbon monoxide poisoning [24]. Both COVID-19 concurrent crises stressed already overextended capabilities of healthcare systems and thus constitute appropriate grounding for the current study.

\section{HEALTHCARE COALITIONS}

When assessing crisis management in the healthcare system in the United States, it is important to note that traditionally the system is ill-equipped to manage disaster preparedness and response. This is due to its dispersed, decentralized nature of various types of healthcare 
facilities, operating mostly at their daily capacities, and mostly in private sector. Conversely, crisis preparedness and response has been associated with management by public agencies at local, state, and federal levels [25]. Case in point, the American Hospital Association listed 6,090 hospitals operating in 2021 of which more than half $(2,946)$ were non-for-profit, nongovernmental community hospitals, 1,233 investor-owned (private) community hospitals [26]. Others fell under local, state, and federal government oversight. Those numbers do not include all other types of institutions that vary in type, funding, ownership, and size such as long-term care facilities for example. In such a landscape, the concept of healthcare coalitions (HCCs) defined as "a formal collaboration among hospitals, public health departments, emergency management and response agencies, and possibly other types of healthcare entities in a community that are organized to prepare for and respond to mass casualty and catastrophic health events" [25, para. 18] has been gaining in popularity, relevance, and governmental support. Clearly, HCCs inherently can build a more resilient community by bringing together the dispersed healthcare community, emergency management organizations, public health officials, first responder agencies, and elected jurisdictional officials to participate in joint trainings and exercises, which in turn results in a more coordinated and cohesive response. In current practice, the US Department Health and Human Service (DHHS) Assistant Secretary for Preparedness and Response (ASPR), a position created under the Pandemic and All Hazards Preparedness Act post-Katrina, provides federal funding to states to develop HCCs that focus on healthcare preparedness and response [26]. By 2020, "the HHS ASPR Hospital Preparedness Program (HPP) reported $85 \%$ of hospitals nationwide participate in HCCs along with $82 \%$ of local health departments, $56 \%$ of emergency management organizations, and $27 \%$ of emergency management services" [27, p. 3]. Even though researchers have recognized the value of coalitions in securing access to resources and political influence [28], [29], and even though the HCC concept appears to have been endorsed nationally, there is paucity of research focusing on healthcare coalitions for emergency management and healthcare resiliency-building specifically. Our study aims to bridge that gap by exploring the role of an HCC in Southeast Texas in building healthcare system resilience during COVID-19 concurrent crises.

The HCC concept of collaborative governance differs from models among countries with socialized medicine. During any disaster that would affect the health and medical area in a country with socialized medicine, the preparedness and response is the responsibility of the government. When a country has privatized medicine, the event or incident starts and ends at the local level, leaving the responsibility of preparedness and response to the individual facilities, cities, and counties. State and federal assistance are provided only when local resources have been or will be exceeded, and a formal request for assistance has been made by the Jurisdiction Having Authority (i.e., Mayor, Governor). Thus, instituting Regional Advisory Councils (RACs) and Medical Operation Centers (MOCs) as central coordination hubs of information, facility status, available resources, critical resource needs, and the singular collective voice for the individual organizations in the health and medical arena, provides a robust regional perspective of the critical healthcare needs and status and allows individual facilities the leverage needed to address these concerns.

During a disaster that affects the health and medical infrastructure in Southeast Texas, the Catastrophic Medical Operations Center (CMOC) is activated and staffed by the SouthEast Texas Regional Advisory Council (SETRAC), a non-profit organization. The Regional Healthcare Preparedness Coalition (RHPC) of which SETRAC is an example, serves as the governing body and adopts a representative form of governance. Due to the sheer size of the region, comparable to the size of Ireland with nearly twice the population, SETRAC divides the 25-county region into five corridors: North, South, East, West, and Downtown (Fig. 1). 
The corridors are based on geographic locations and common risks and hazards. Each corridor has an elected official (Corridor Chair) who in turn represents the interests of all healthcare agencies in that corridor on the RHPC governing board. Each Corridor meets every other month to address preparedness or response-related issues. The RHPC Board provides the strategic vision and overall priorities of preparedness and response (trainings, regional plans, exercises) for the Corridors to implement at the local level. The CMOC serves as the resource and coordination hub for the 25-county area by (a) collecting/disseminating information; (b) planning for the next operational period from a regional perspective; (c) coordinating with other stakeholders outside of health and medical sectors; (d) providing resources; (e) anticipating resource needs; (f) providing logistical support; and (g) centralizing the coordination of patient movement and repatriation. An example of this was the COVID-19 response and the concurrent disasters within.

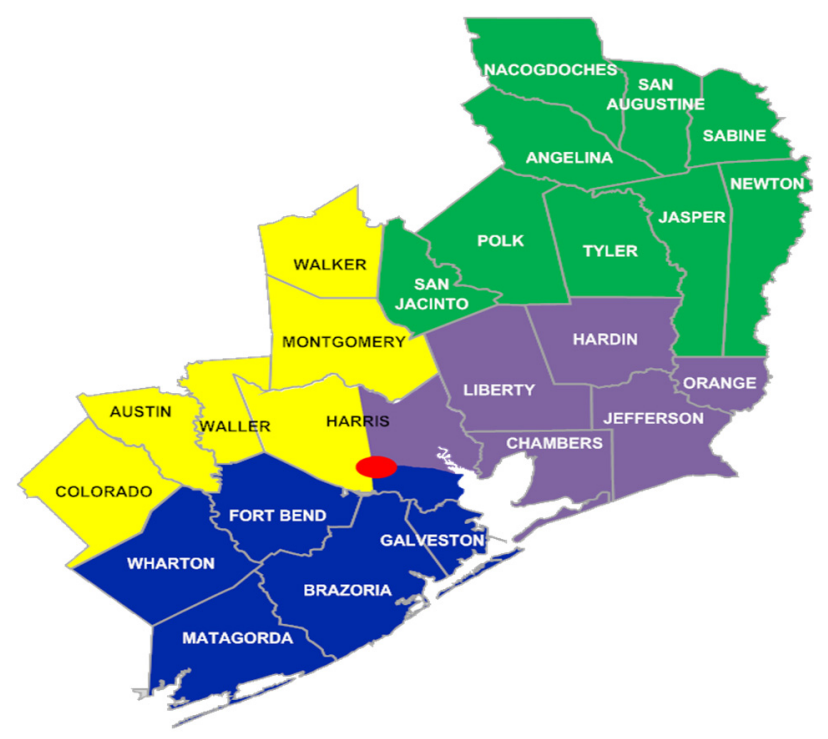

Figure 1: SETRAC regional coverage. Note: Yellow $=$ West Corridor; Blue $=$ South Corridor; Red $=$ Downtown Corridor; Purple $=$ East Corridor; and Green $=$ North Corridor.

From March 2020 to July 2021 the CMOC was activated and staffed by SETRAC for COVID-19, Tropical Storm Beta, Hurricane Laura, civil protests in Houston, and Winter Storm Uri; each crisis presented unique sets of compounding challenges for the health and medical infrastructure of Southeast Texas. The role of SETRAC in the COVID-19 response was twofold: (a) monitoring healthcare capacity and building surge capability; and (b) distributing personal protective equipment (PPE) to healthcare agencies. Subsequently, SETRAC created a public PowerBI report which monitored COVID-19 hospitalization and bed capacity data. Daily each healthcare organization would complete a series of 137 questions eliciting data which would be corroborated by SETRAC and visualized on the public PowerBI COVID reports. Moreover, SETRAC was responsible for distributing PPEs throughout the SETRAC 25-county region to all healthcare organizations (to include dentists) through a "push pack" model. A push pack is a predesignated allotment of PPE based on the 
facility type, size, and inventory that SETRAC had received from the State of Texas. Facilities or agencies then were given a three-day window to come and pick up the PPE (Fig. 2 shows PPE distributed as of 22 May 2021). Coincident to tracking healthcare capacity via data collection and visualization, as well as PPE distribution, COVID-19 concurrent disasters such as Hurricane Laura, and Winter Storm Uri required SETRAC to expand additional support to healthcare infrastructure. Conceptualizing the role of $\mathrm{HCC}$ as fostering healthcare system resilience, we adopt the concept of linking [30] under which social capital gets strengthened by vertical ties that allow access to information, knowledge, resources, and influence. This research focuses on two questions specifically: (a) What are the capabilities of SETRAC as an HCC that strengthened the overall regional healthcare system resiliency during COVID-19 concurrent crises? and (b) What are the SETRAC's capabilities in need of strengthening during COVID-19 concurrent crises in order to make the regional healthcare system more resilient?

\begin{tabular}{|c|c|c|c|c|c|c|c|c|c|}
\hline Facility Type & Total N95 Mask & Coveralls & Face Shields & Total Gowns & Surgical Mask & Gloves & Shoe Covers & Non-Medical Gloves & Goggles \\
\hline Clinic/Physician Office & $3,406,566$ & 676 & 141,302 & 398,736 & $8,189,600$ & $7,099,184$ & 1,612 & 2 & 5,632 \\
\hline Dialysis & 46,660 & 385 & 766 & 6,302 & 70.050 & 20,720 & 0 & 0 & 0 \\
\hline First Responders & $4,448,598$ & 98,895 & 106,978 & 226,095 & $8,089,900$ & $4,691,490$ & 4,500 & 0 & 50,173 \\
\hline Home Care Senvices & $3,328,460$ & 2,425 & 57,493 & 268,051 & $7,052.810$ & $3,718,770$ & 175 & 0 & 920 \\
\hline Hospital & $5,636,796$ & 93,072 & 293,397 & 252,804 & $13,529,655$ & $5,128,692$ & 363,400 & 0 & 1,720 \\
\hline Jurisdictions & 1.589 .926 & 77,410 & 244.144 & 782,731 & $3,530,730$ & $2,450,200$ & 6,700 & 197,500 & 52,235 \\
\hline LTAC & 353,630 & 1.745 & 16.578 & 29.286 & 610,550 & 314,400 & 8.601 & 9 & 0 \\
\hline LTC & $\cdot 4,654,003$ & 24,584 & 71,808 & 481,887 & $10,416,101$ & $6,644,409$ & 14,852 & 0 & 570 \\
\hline Other & 66,680 & 650 & 3,546 & 8.451 & 109,400 & 139,650 & 150 & 10,000 & 570 \\
\hline Pharmacy & 95.230 & 0 & 3,968 & 18.405 & 213,600 & 61,300 & 0 & 0 & 0 \\
\hline Total & $23,626,549$ & 299,842 & 939,980 & $2,472,748$ & $51,812,396$ & $30,268,815$ & 399,990 & 207,511 & 111,820 \\
\hline
\end{tabular}

Figure 2: SETRAC PPE distribution chart. Note: Clinic/physician office includes dentists; First responders includes EMS, fire and law enforcement; Home care services includes home health, hospice, and personal care agencies; LTC includes assisted living, skilled nursing, intermediate care, community care retirement, and inpatient hospice; LTAC includes specialty hospitals, behavioral hospitals, long term acute rehabilitation; Hospitals include freestanding ERs and urgent care facilities; Jurisdictions include city, county and tribal.

\section{METHODOLOGY AND ANALYSIS}

A survey design was implemented to examine data from Hurricane Laura, and Winter Storm Uri in Southeast Texas. Surveys constitute the most used research design in healthcare epidemiology research because of the low-cost, convenience, and willingness of respondents to share information without interviewers' present [31]. In tandem, an analysis of research methodology in health services found that qualitative methods are widely used and accepted in healthcare research [32]. Most recent COVID-19 study in Italy [33] adopted a survey design in healthcare as well. The methodology for collection comes as standard SETRAC. AAR institutional practice in that post-disaster or activation of the CMOC, all members of the healthcare coalition are sent an online link to answer questions about (a) individual facility strengths or weaknesses; (b) regional strengths or weaknesses; (c) the number of participating staff; (d) areas for improvement; (e) identification whether the facility utilized the CMOC when issues arose; and (f) name, Facility name, contact information, and Corridor. Even though overall, there were 16 open-ended questions on the Winter Storm Survey, and 14 on the Hurricane Laura Survey, our analysis focused on extraction of data from two items relevant to answering our research questions, namely (a) Identify areas of SETRAC strength in support to Hurricane Laura/Winter Storm Uri; and (b) Identify areas for improvement based on SETRAC support to Hurricane Laura/Winter Storm Uri. 
Participation in AAR surveys is optional to all facilities; however, healthcare organizations that do participate are included in the SETRAC regional AAR. Notably, participation in a community based full-scale exercise and after-action conference is one of the Conditions of Participation a hospital must fulfil to maintain Center for Medicare and Medicaid Services (CMS) compliance [34]. The process for completing the AAR is as follows: A disaster occurs or the CMOC is activated, once the CMOC is demobilized the AAR questionnaire is sent out to all health organizations and stakeholders with a completion deadline. Subsequently, results inform the After-Action Conference which is a 4 hour meeting for all respondents to clarify or discuss strengths, weaknesses, and areas for improvements. Individual corridor meetings follow to discuss any issues in greater detail as they pertain to that geographic region. After the After-Action Conference and Corridor Meetings the AAR is completed and posted to the SETRAC website for all members to download. This document compliments the organization specific AAR that each organization has the choice of completing.

This research evaluated the 403 survey responses from the Hurricane Laura and 399 survey responses from the Winter Storm Uri AAR questionnaires and separated the organizations based on Corridor (North, South, East, West, Downtown). In total SETRAC has 1,561 total active members receiving the instrument. The Hurricane Laura survey was completed between 10 September 2020 and 15 October 2020 (with two late submissions). The Winter Weather survey was completed between 22 February 2021 and 29 March 2021 (with three late submissions). Overall, the response rate for the Hurricane Laura survey was calculated at $25.6 \%$ and the response rate for the Winter Storm Uri survey at $25.8 \%$; as typical return rates in healthcare survey studies is $20-30 \%$ [31], our data fall within accepted range and can be viewed as representative of the Coalition and reliable. Figs 3 and 4 offer a breakdown of healthcare organizations' surveys collected for Hurricane Laura and Winter Storm Uri by agency type, respectively for each. Of the 403 responses from the Hurricane Laura survey 26 were in the North Corridor, 137 in the South Corridor, 66 in the East Corridor, 136 in the West, and 38 in the Downtown Corridor. Of the 399 Winter Storm Uri responses 26 responses were in the North Corridor, 126 were in the South Corridor, 50 in the East Corridor, 148 were in the West Corridor, and 49 in the Downtown Corridor.

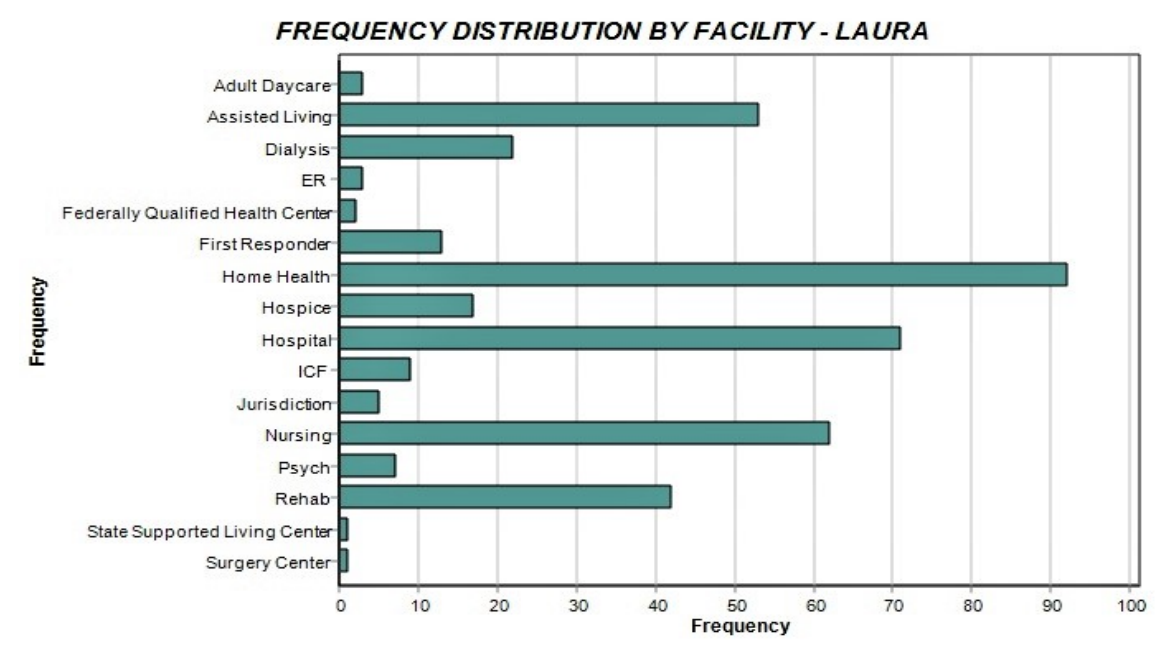

Figure 3: Frequencies of Hurricane Laura survey responses by agency type. (Source: $Q D A$ Miner.) 


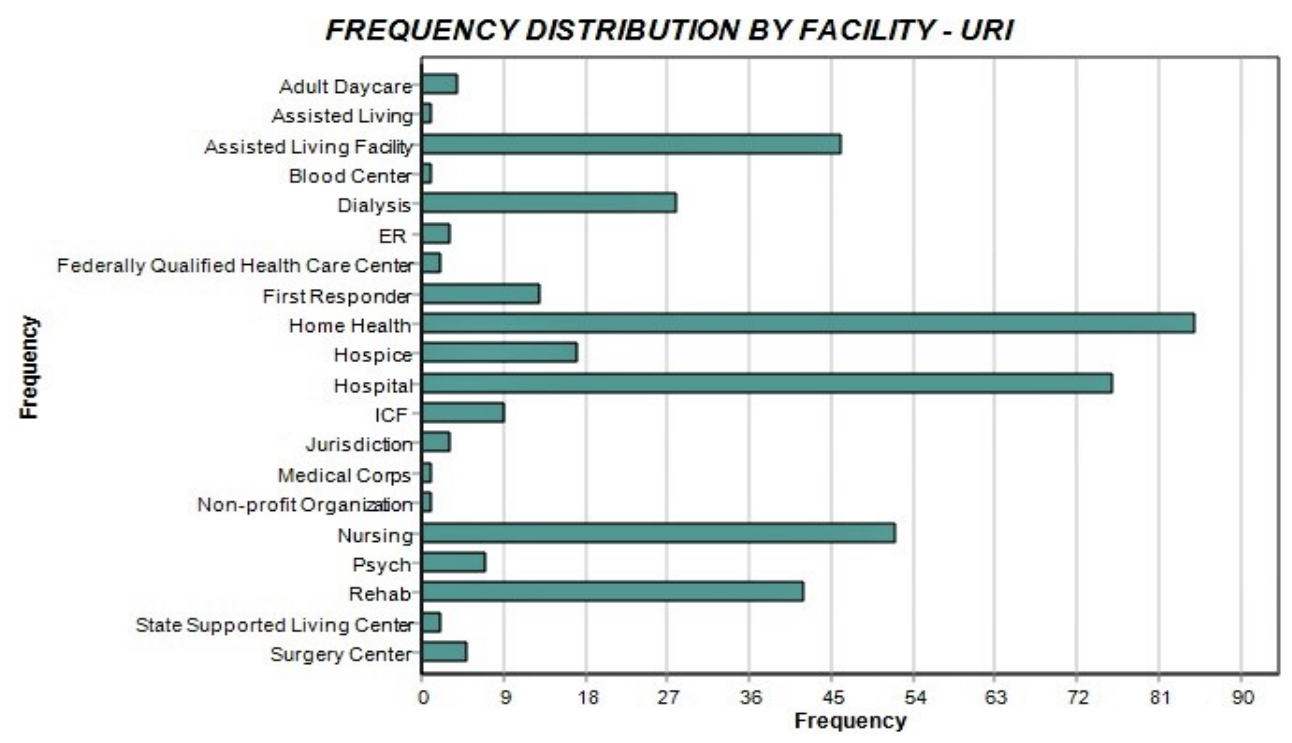

Figure 4: Frequencies of Winter Storm Uri survey responses by agency type. (Source: QDA Miner.)

Surveys, originally collected in Excel, were inputted into QDA Miner [35] - qualitative data analysis software - to enable classical constant comparison analysis [36], [37]. QDA Miner has been used for qualitative analyses both in disaster studies and healthcare [38]-[40] and it allows for categorization and codification of data into thematic units which in our study occurred a posteriori (identification and categorization of codes followed data-driven analysis and included assessing frequency, salience, distribution, and commonality among others). Further, the software offers functionality to split codes, rename codes, merge codes, subcategorize codes, all of which are effective means for ensuring consistency and integrity when managing a robust corpus of qualitative data. Data for each COVID-19 concurrent crisis were first categorized and coded independently form one another. This was aimed at eliminating potential transference effects; because the two events were triggered by two different hazards and two different levels of regional familiarity, we wanted to capture potential nuances. Once both cases were coded independently, we conducted cross-case evaluation for similarities and differences. Thus, the classical content analysis process was iterative and coordinated among research team members to ensure saturation and qualitative inter-rater reliability.

\section{RESULTS}

This study gauged participating healthcare organizations' perceptions about SETRAC's role in supporting organizational resiliency during two COVID-19 concurrent crises. In response to research question 1: What are the capabilities of SETRAC as an HCC that strengthened the overall regional healthcare system resiliency during COVID-19 concurrent crises, data analysis for survey responses from Hurricane Laura yielded eight final codes: (a) Communication; (b) Relationship links; (c) Accessibility; (d) Excellence; (e) Organization; (f) Reliability and knowledge; (g) Engagement; and (g) Resource management. Fig. 5 illustrates frequencies of codes across cases under analysis. 


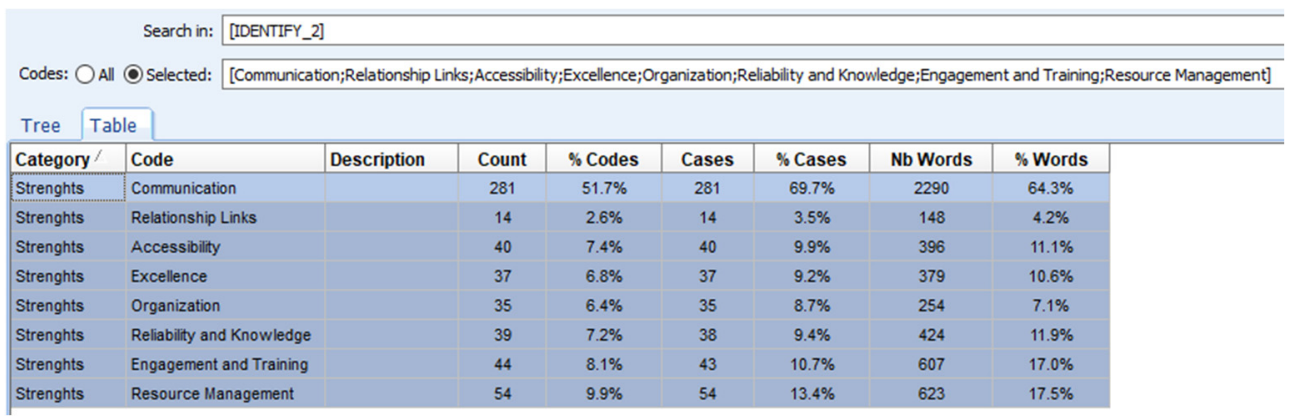

Figure 5: Analysis results of SETRAC strengths during Hurricane Laura. (Source: QDA Miner.)

Because communication and resource codes had two highest frequencies, specific breakdown of their types represented is provided by Fig. 6 for communication types and Fig. 7 for resource types.

\section{COMMUNICATION TYPES - HURRICANE LAURA}

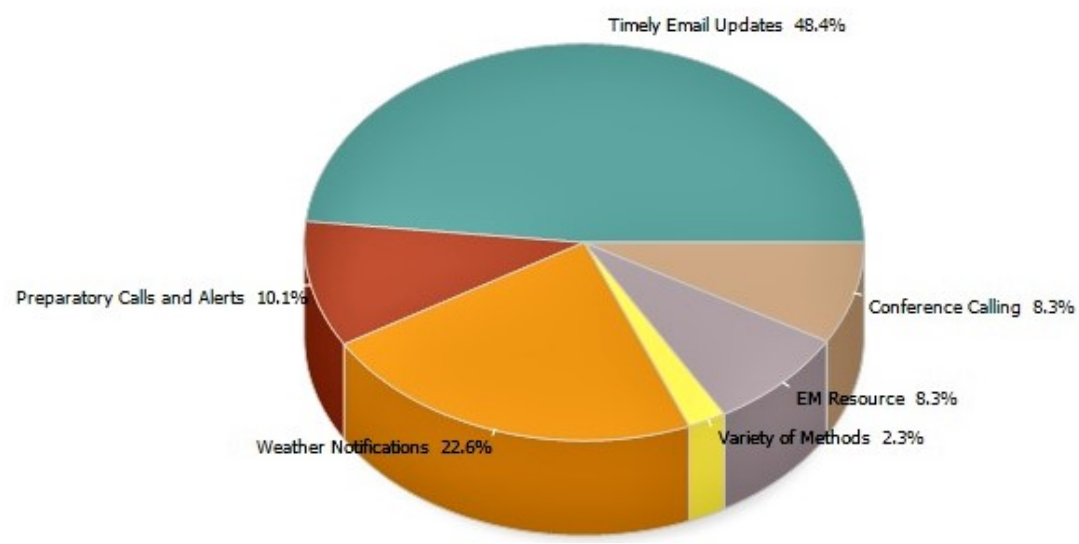

Figure 6: Types of SETRAC communications during Hurricane Laura. (Source: QDA Miner.)

Question 1 responses from Winter Storm Uri yielded eight final codes: (a) Communication; (b) Resource management; (c) Availability; (d) Training; (e) Reliability and knowledge; (f) Service orientation; (g) Relationship links; and (h) Organization. Fig. 8 illustrates frequencies of codes across cases under analysis.

Similarly, as communication and resource management were predominant, we offer more granular breakdown represented by Fig. 9 for communication types and Fig. 10 for resource types. 


\section{RESOURCE TYPES - LAURA}

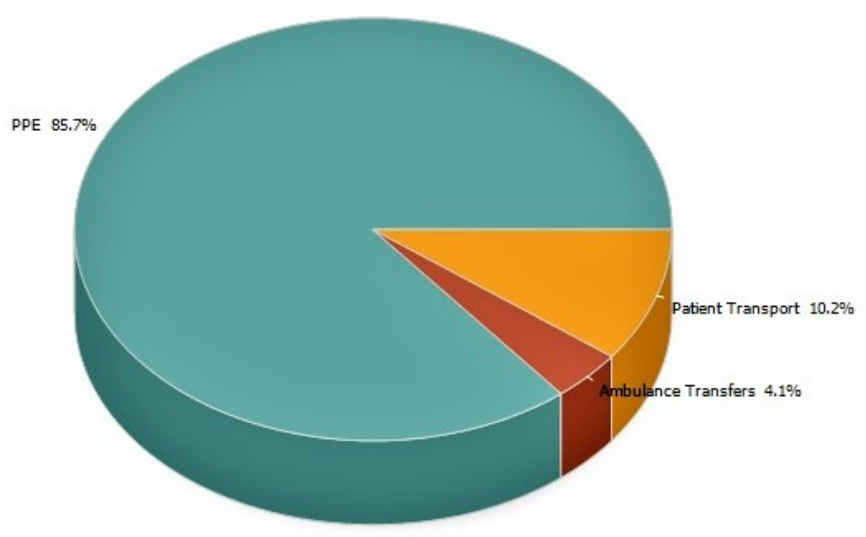

Figure 7: Types of resources provided by SETRAC during Hurricane Laura. (Source: QDA Miner.)

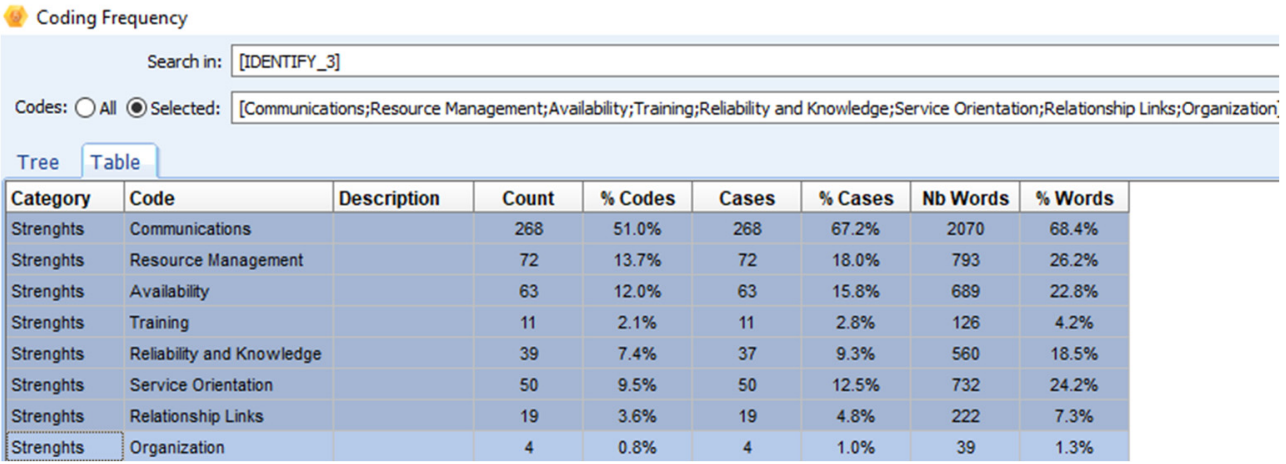

Figure 8: Analysis results of SETRAC strengths during Winter Storm Uri. (Source: QDA Miner.)

The distribution of strengths based on agency type is represented by Fig. 11 for Hurricane Laura, and by Fig. 12 for Winter Storm Uri, respectively.

In response to research question 2: What are the SETRAC's capabilities in need of strengthening during COVID-19 concurrent crises in order to make the regional healthcare system more resilient? Our analysis revealed six codes for Hurricane Laura as represented by Fig. 13: (a) Communications; (b) Identifying, securing, prepositioning resources; (c) Inclusivity and integration; (d) More training; (e) Evacuation preparedness; and (f) Technical improvements. For Winter Storm Uri we discerned the following five thematic categories: (a) Special resources; (b) Communications; (c) Patient transfers; (d) Inclement weather preparedness training; and (e) Inclusion summarized in Fig. 14. 


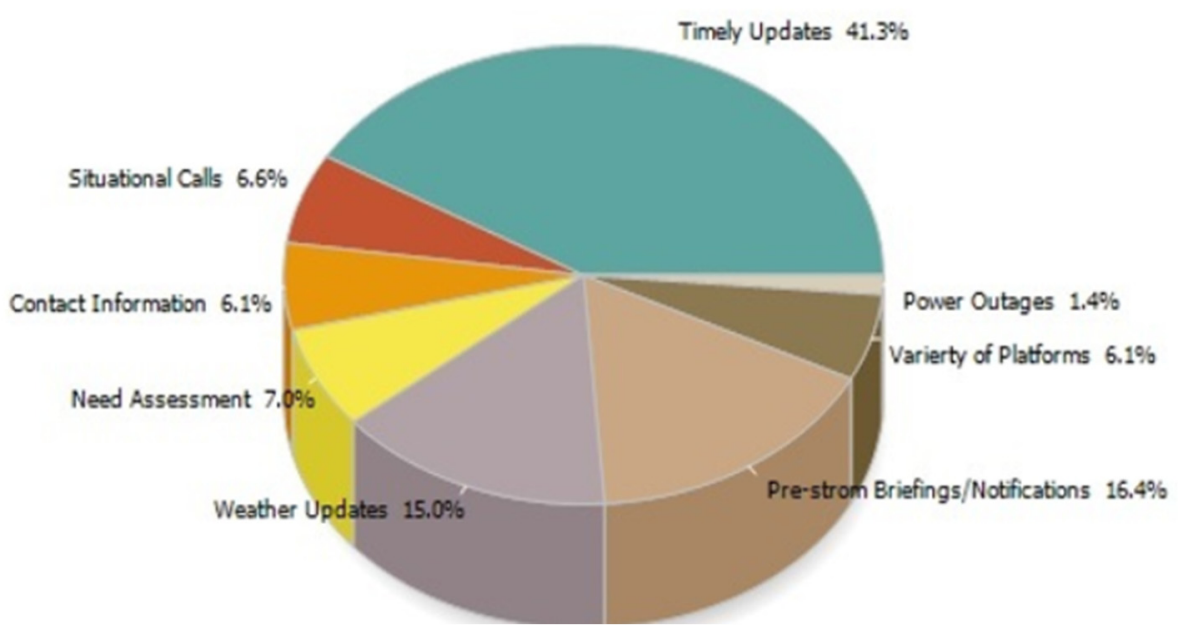

Figure 9: Types of SETRAC communications during Winter Storm Uri. (Source: QDA Miner.)

\section{RESOURCE TYPES - URI}

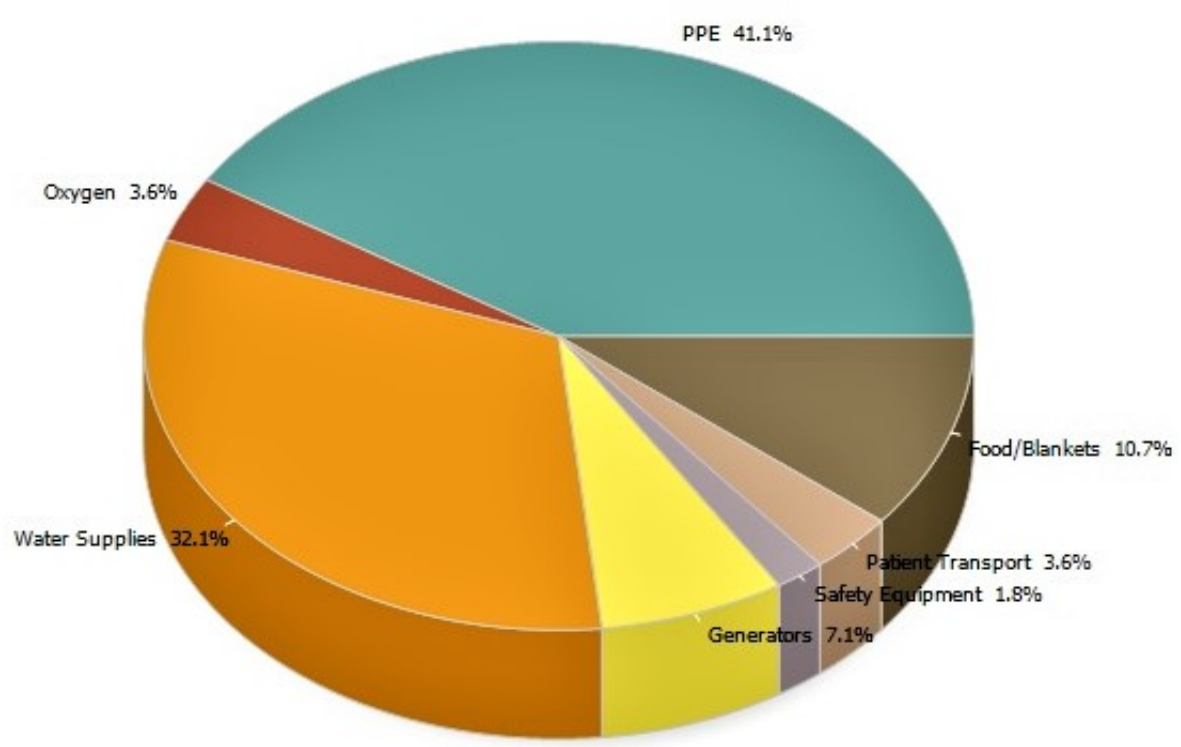

Figure 10: Types of resources provided by SETRAC during Winter Storm Uri. (Source: QDA Miner.) 


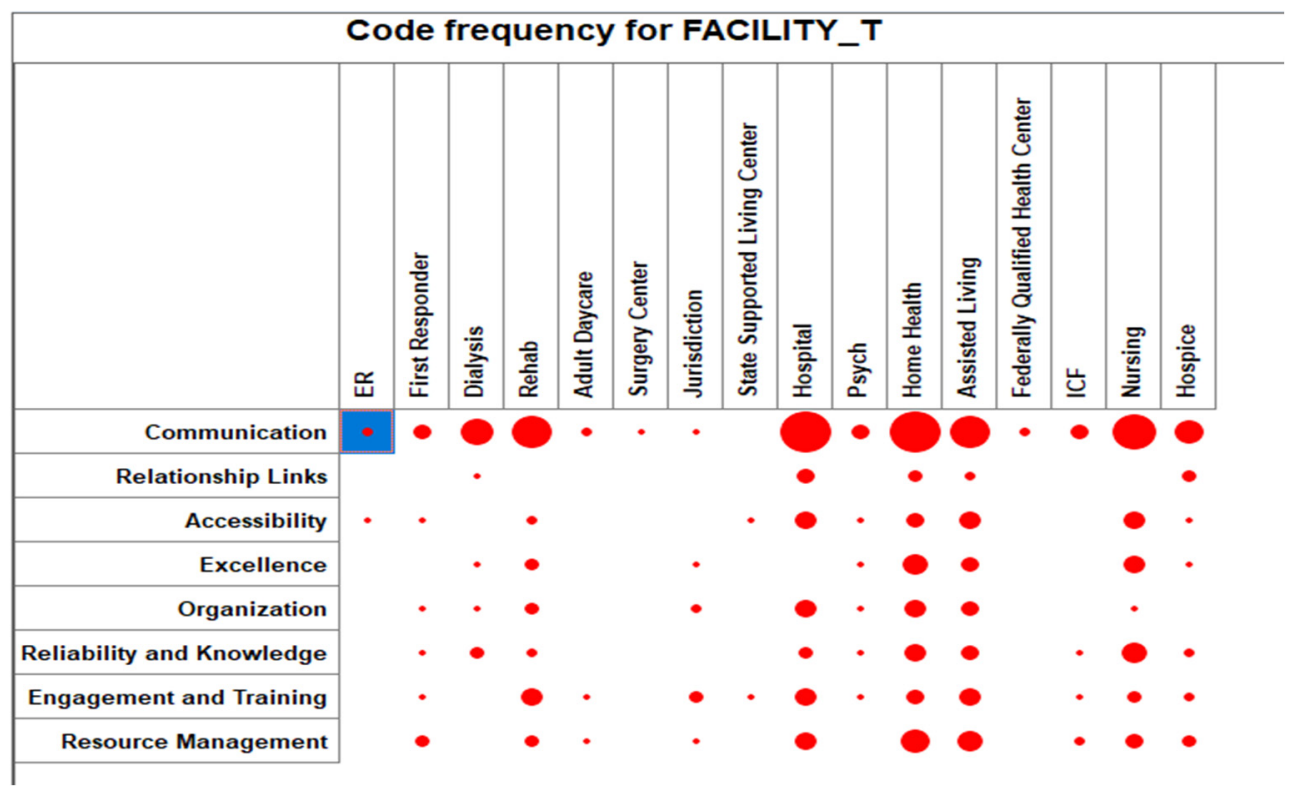

Figure 11: SETRAC strengths during Hurricane Laura recognized by agency type. (Source: QDA Miner.)

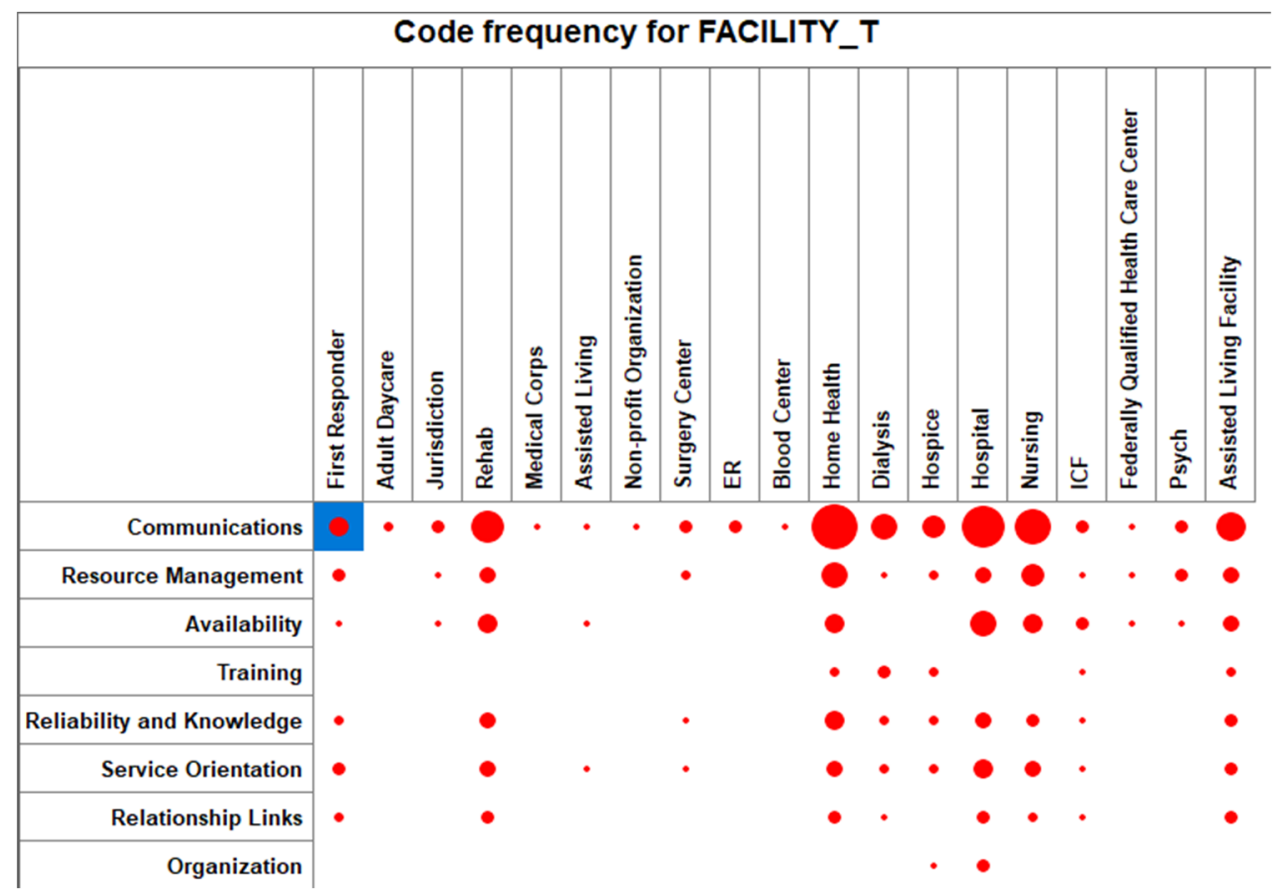

Figure 12: SETRAC strengths during Winter Storm Uri recognized by agency type. (Source: QDA Miner.) 


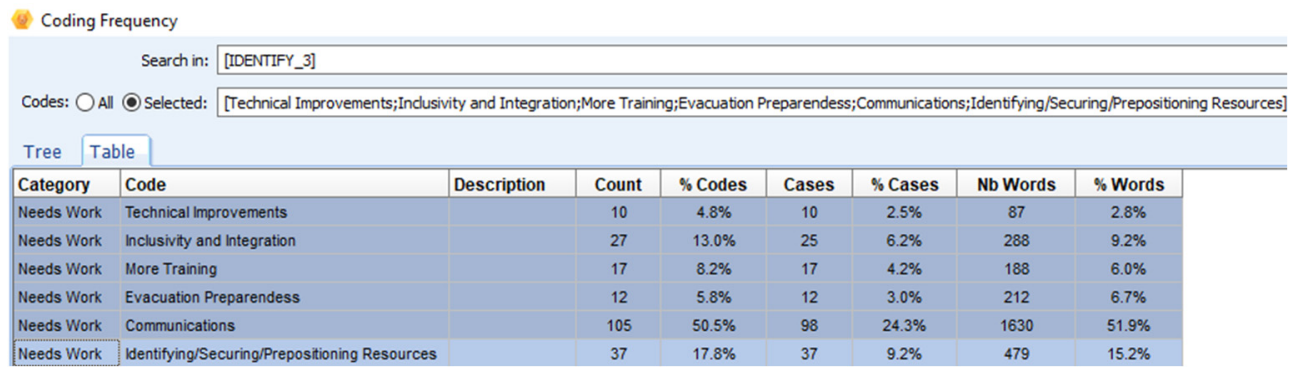

Figure 13: Analysis results for SETRAC areas in need of improvement during Hurricane Laura. (Source: QDA Miner.)

\begin{tabular}{|c|c|c|c|c|c|c|c|c|c|c|}
\hline \multirow{2}{*}{\multicolumn{2}{|c|}{$\begin{array}{l}\text { Search in: } \\
\text { Codes: OAll O Selected: }\end{array}$}} & \multirow{2}{*}{$\begin{array}{l}\text { Search in: } \\
\text { Selected: }\end{array}$} & \\
\hline & & & \multicolumn{8}{|c|}{ [Special Resources;Communcations;Patient transfers;Indement Weather Preparedness/Training;Inclusion] } \\
\hline Tree & $T$ & & & & & & & & & \\
\hline \multicolumn{2}{|c|}{ Category } & \multicolumn{2}{|l|}{ Code } & Description & Count & $\%$ Codes & Cases & $\%$ Cases & Nb Words & $\%$ Words \\
\hline \multicolumn{2}{|c|}{ Challenge } & \multicolumn{2}{|c|}{ Special Resources } & & 71 & $34.0 \%$ & 64 & $16.0 \%$ & 875 & $32.7 \%$ \\
\hline \multicolumn{2}{|c|}{ Challenge } & \multicolumn{2}{|c|}{ Communcations } & & 75 & $35.9 \%$ & 74 & $18.5 \%$ & 1013 & $37.9 \%$ \\
\hline \multicolumn{2}{|c|}{ Challenge } & \multicolumn{2}{|c|}{ Patient transfers } & & 8 & $3.8 \%$ & 8 & $2.0 \%$ & 200 & $7.5 \%$ \\
\hline \multicolumn{2}{|c|}{ Challenge } & \multicolumn{2}{|c|}{ Inclement Weather Preparedness $/$ Training } & & 28 & $13.4 \%$ & 26 & $6.5 \%$ & 344 & $12.9 \%$ \\
\hline \multicolumn{2}{|c|}{ Challenge } & Inclusion & & & 27 & $12.9 \%$ & 27 & $6.8 \%$ & 355 & $13.3 \%$ \\
\hline
\end{tabular}

Figure 14: Analysis results for SETRAC areas in need of improvement during Winter Storm Uri. (Source: QDA Miner.)

Finally, Figs 15 and 16 illustrate distribution of categories based on agency type for Hurricane Laura and Winter Storm Uri, respectively.

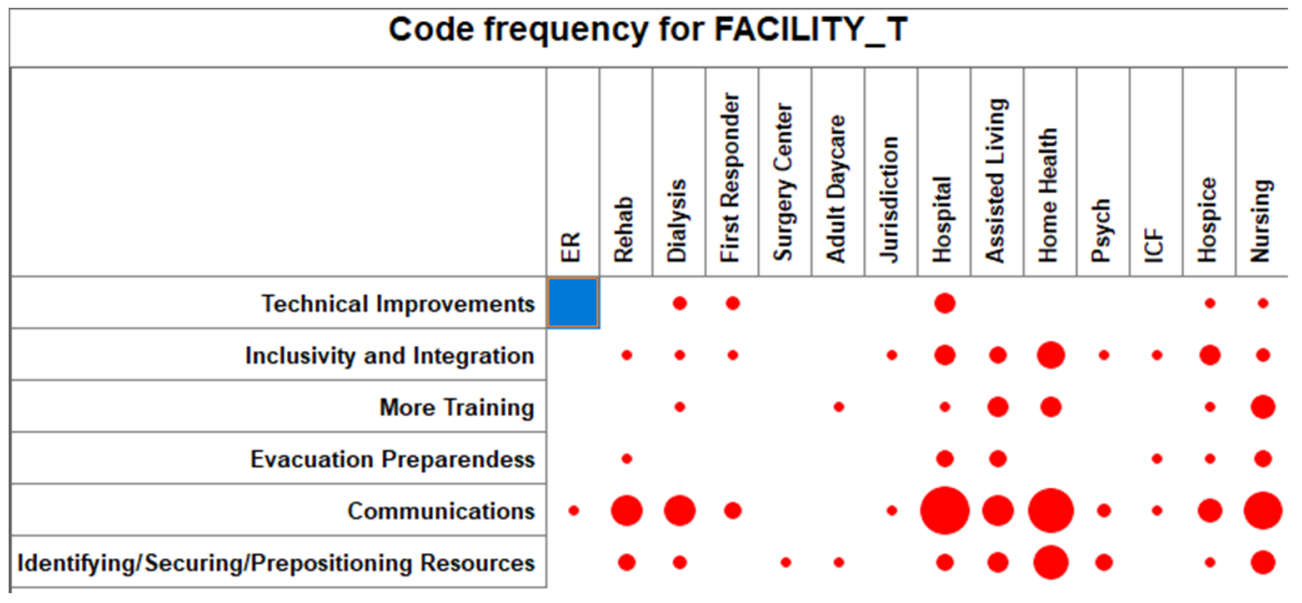

Figure 15: SETRAC's areas for improvement during Hurricane Laura by agency type. (Source: QDA Miner.) 


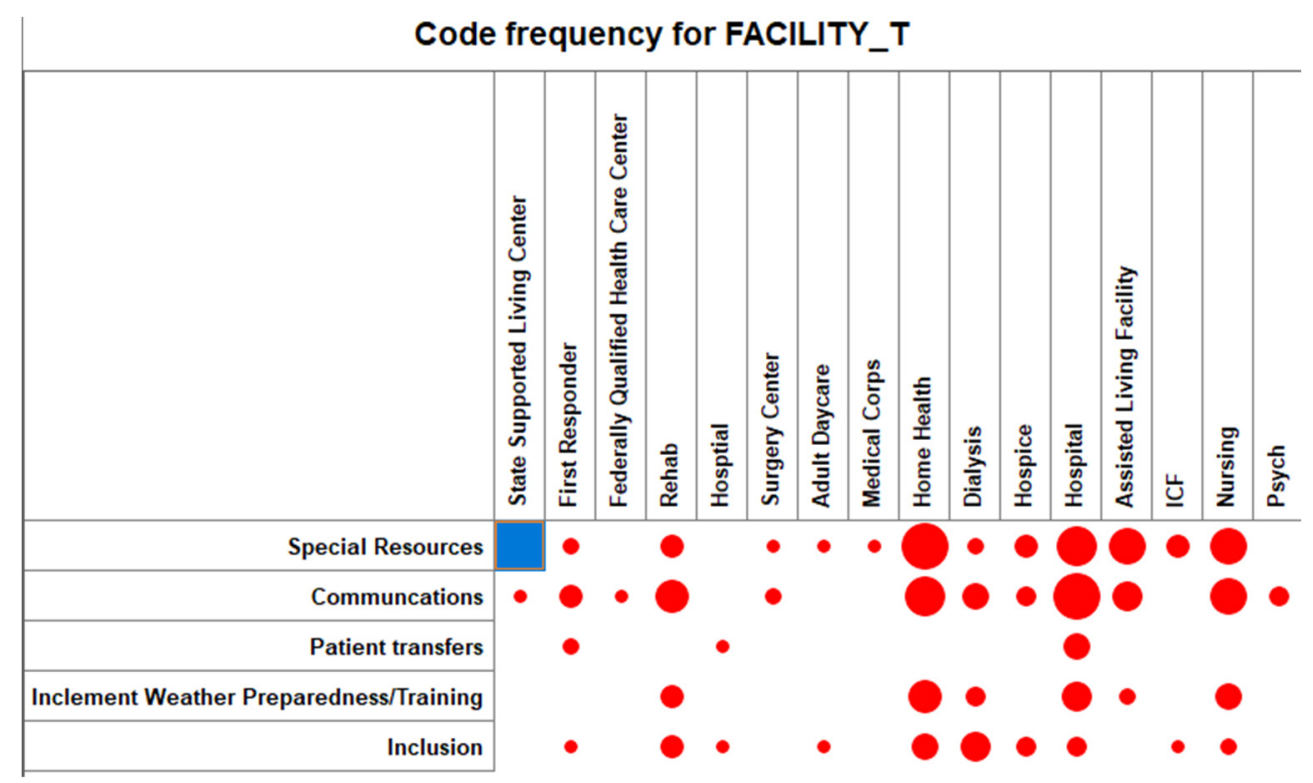

Figure 16: SETRAC's areas for improvement during Winter Storm Uri by agency type. (Source: QDA Miner.)

\section{DISCUSSION AND IMPLICATIONS}

The results of our study point to SECTRAC HCC as a formidable force for information sharing through Communications during COVID-19 concurrent crises. During Hurricane Laura, nearly $70 \%$ of respondents discussed the impact of communications on their ability to make disaster decisions. Among communication types, nearly half of the participating agencies $(48.4 \%)$ stressed the value of constant emails with timely updates about the regional healthcare system situation prior to and during the storm; moreover, nearly quarter of the participants $(22.6 \%)$ specifically stressed the enormous value of timely and credible weather reports (compiled for healthcare and based on National Weather Service (NWS) and other meteorological outlets). Continuous and reliable weather updates were critical because the path of the Hurricane Laura was constantly changing, and evacuation decisions were predicated based on the most realistic and probable landfall location; because of COVID-19, evacuation decisions were the issue of last resort for most healthcare agencies in the region. Thus, gauging the situational email updates that addressed among others COVID-19 area status as well as continuous weather tracking allowed for balanced approach to necessity of evacuation and measures/considerations during potential evacuation. In many surveys, participants stressed that they did not possess the capacity, nor the expertise to assess the situation on their own and they were already short-handed preparing themselves and patients for continuity of operations internally. Public media outlets were cited as highly unreliable for decisions in healthcare system as they lacked required strategic regional healthcare focus and specificity. Moreover, SETRAC's continually updated emergency resource management platform, was instrumental for situational awareness about regional resources while multiple communication modes (emails, calls, website, conference, webinars, or narrated PowerPoints) were also listed as invaluable. Markedly, more than $10 \%$ of those surveyed stressed the value of SETRAC's preparatory calls and alerts which provided a strategic 
picture for expectations, operations, collaborative capacities, and potential challenges during the storm. Finally, regular conference calls held by SETRAC allowed for continuous engagement and keeping stock of the situation as it unfolded.

For Winter Storm Uri, nearly $70 \%$ of participating agencies selected SETRAC communications as the biggest asset to them during this COVID-19 concurrent crisis as well. Beyond email updates and weather notifications though, communication types represented slightly different anatomy; particularly, pre-event notifications and alerts were given more weight as critical during Winter Storm Uri. The proactive focus by SETRAC in this crisis is particularly noteworthy because of hazard novelty. Moreover, SETRAC particularly engaged in individual situational calls and needs' assessments to gauge status of specific facilities those were found critical by many because of the unprecedented nature of the crisis as well. In tandem, contact information and power outage information supplied by the coalition were listed as valuable. Communication differences, albeit subtle point to SETRAC's ability as a governance model to adapt in chaotic systems (something that is very difficult for traditional and centralized bureaucratic structures).

Notably, SETRAC was instrumental in resource identification, management, and fair and equitable distribution. Indeed, Resource Management was the second most common category of disaster capacity created by SETRAC for healthcare system in the region. For Hurricane Laura, more than $85 \%$ of the healthcare entities confirmed dire need, request, and subsequent receipt of PPE by the coalition; PPE supplies were indeed critical during Hurricane Laura as the hurricane cooccurred at the tail end of the first phase of the pandemic. Moreover, when evacuations were necessary, SETRAC facilitated ambulance transfers and provided patient transport as indicated by those surveyed. Resource Management in Winter Storm Uri, second only to Communications, was discussed by nearly one-fifth of respondents (18\%). Interestingly, during Winter Storm Uri less than half of respondents than in Hurricane Laura expressed dire need, requested, and receipt of PPE supplies; this is understandable as in midFebruary of 2021 Texas was two months into mass vaccination process and supply needs were slowly being met (albeit that number was still at more than $40 \%$ ). However, SETRAC was cited as absolutely critical to providing needed water supplies to many healthcare system entities that lost power and had catastrophic pipe breakage. Moreover, specialized resources such as food items, generators, blankets, safety equipment were also provided. Admittedly, needs and concerns during Winter Storm Uri were vastly different from those encountered during the hurricane.

Beyond communication and resource management, during Hurricane Laura SETRAC was credited with Reliability and Knowledge - this theme related to trust in all communications provided by the coalition and value of disaster management expertise at the local, state, and federal level that they possess and were able to share. Engagement and Training - was the category mentioned by more than $10 \%$ of those surveyed; inarguably, SETRAC's regional engagement in disaster planning and preparedness to include joint trainings, conferences, and scenarios fostered capabilities such as presence of emergency plans, or general disaster awareness many agencies leveraged during the hurricane. Accessibility related to SETRAC's access by phone, email, or conference call on moment's notice - this was confirmed by nearly $10 \%$ of agencies as mission-critical. In nearly every case described under this theme, respondents expressed the value of getting a hold of coalition's representative in the very middle of the crisis. Both Excellence and Organization themes expressed gratitude for leadership and high level of organization. Finally, a small cluster emerged among analysed responses that listed very specific Relationship Links created by SETRAC for participating agencies that were found valuable. It is quite significant that both home health and assisted living facilities were two categories of responders by whom all those themes were listed as 
critical even though hospitals, hospices, nursing homes, and rehabilitation centres endorsed the majority of SETRAC-created resiliency capabilities as well, thus underscoring the coalition's relevance as a resilience builder across a wide range of healthcare system entities.

Beyond Communication and Resource Management, during Winter Storm Uri several themes such as Reliability and Knowledge, Training, Organization, and Relationship Links speak to similar resilience capabilities as those discussed during Hurricane Laura. Two dimensions, however, reveal a slightly different assessment of SETRAC's value in Winter Storm Uri as compared with the hurricane. Notably, Service Orientation was the category clearly discernible in Winter Storm Uri data. Survey participants expressed gratitude for help, empathy, courtesy, understanding, compassion, and support by SETRAC. Even though very nuanced, this difference is important as it points to SETRAC's ability to adapt situationally - in Winter Storm Uri, more individualized approach was needed to reassure, and support healthcare partners as the event was out of the ordinary realm of cyclical hurricane. Aligned with that interpretation is the theme Availability; while in Hurricane Laura SETRAC was cited as Accessible at a moment's notice, in Winter Storm Uri the coalition actively engaged with entities needed support as they were Available to take on novel tasks (such as water distribution) as needed. As in Hurricane Laura, Home Health, Assisted Living Facilities, or Hospitals attached importance to most of the resilience capabilities created by SETRAC while other agencies such as emergency rooms (ERs) benefitted the most from specific capability only (i.e., communications).

Coincidentally, Communications and Resource Management categories were also those categories that emerged as needing ongoing strengthening. Interestingly, during Hurricane Laura responders pointed to the need for text communication as an alternative to phone, conference, or email formats and many stressed technical and scheduling problems with conference calls as well as the need for better dissemination of contact information. It appears as those were resolved by SETRAC by February as most comments about Communication after Winter Storm Uri discussed issues related to lack of information and warnings related for example to city's issuance of such (e.g., water boil ordinance). For resource management, most of strengthening in both crises related to either pre-positioning of resources or better, more robust access to specialized resources such as transportation or generators. After Hurricane Laura, agencies stressed the need for more evacuation planning under pandemic conditions and after Winter Storm Uri more planning, training, and preparedness for adverse/inclement (non-hurricane) weather events. It is noteworthy that most comments within these analysed about SETRAC's improvements referred to building on existing capabilities. Perhaps the most notable in our assessment was the need expressed both in Hurricane Laura and Winter Storm Uri (13\% or more in each event) for better agency inclusion. New, small, or non-traditional agencies such as law enforcement or dialysis were particularly interested in being more included and represented in SETRAC's outreach network, training, and relationship links. They also expressed the need for mass communication such as emails or weather updates to include specific content better tailored to their unique needs.

The implications of our study are twofold. First, based on findings related to an HCC operating in the largest medical centre in the world, we confirm that during concurrent disaster events in the United States, healthcare coalitions do fulfil a resilience-building mission. In fact, communication and resource management stewarded by SETRAC align with desired core missions [41] of healthcare coalitions. Moreover, relationship links, organizational structure, domain disaster expertise, or training provided by SETRAC are consistent with the concept of linking for social capital in disasters [30], [42]. The second implication is that SETRAC offers a promising adaptable governance model for the 
successful integration of decentralized, varied mission, varied jurisdiction, and varied service-type entities in healthcare system as represented by the sample used in this study. This is particularly important due to historical marginalization and exclusion of healthcare system agencies like long-term care facilities [43] or home care facilities [44] in disaster management in the United States.

\section{REFERENCES}

[1] Fakhruddin, B., Blanchard, K. \& Ragupathy, D., Are we there yet? The transition from response to recovery. Progress in Disaster Science, 7, pp. 1-5, 2020.

DOI: $10.1016 /$ j.pdisas.2020.100102.

[2] Trump, B.D. \& Linkov, I., Risk and resilience in the time of the COVID-19 crisis. Environment Systems and Decisions, 40, pp. 171-173, 2020.

DOI: 101007/s10669-020-09781-0.

[3] Potutan, G. \& Arakida, M., Evolving disaster response practices during COVID 19 pandemic. International Journal of Environmental Research and Public Health, 18, pp. 1-11, 2021. DOI: 10.3390/ijerph18-63137.

[4] Robinson, L. et al., Cascading crises: Society in the age of COVID-19. American Behavioral Scientist, pp. 1-15, 2021. DOI: 10.1177/00027642211003156.

[5] Kouadio, I.K., Aljunid, S., Kamigaki, T., Hammad, K. \& Oshitani, H., Infectious diseases following natural disasters: Prevention and control measures. Expert Review of Anti-infective Therapy, 10, pp. 95-104, 2012. DOI: 10/1586/eri.11.155.

[6] Simonovic, S.P., Kundzewicz, Z.W. \& Wright, N., Floods and the COVID-19 pandemic: A new double hazard problem. WIREs Water, Wiley, pp. 1-18, 2020.

DOI: $10.1002 /$ wat2.1509.

[7] Quigley, M.C., Attanayake, J., King, A. \& Prideaux, F., A multi-hazards earth science perspective on the COVID-19 pandemic: The potential for concurrent and cascading crises. Environmental Systems and Decisions, 40, pp. 199-215, 2020.

DOI: 10.1007/s10669-020-09772-1.

[8] Finzi, Y., Ganz, N., Limon, Y. \& Langer, S., The next big earthquake may inflict a multi-hazard crisis: Insights from COVID-19 - Extreme weather and resilience in peripheral cities in Israel. International Journal of Disaster Risk Reduction, pp. 1-9, 2021.

[9] Čivljak, R., Markotić, A. \& Capak, K., Earthquake in the time of COVID-19: The story from Croatia (CROVID20). Journal of Global Health, 10(1), 2020.

DOI: $10.7189 /$ jogh.10.010349.

[10] Atalić, J., Uroš, M., Šavor Novak, M., Demšić, M. \& Nastev, M., The $\mathrm{M}_{\mathrm{w}} 5.4$ Zagreb (Croatia) earthquake on March 22, 2020: Impacts and response. Bulletin of Earthquake Engineering, pp. 1-29, 2021. DOI: 10/1007/s10518-021-01117-w.

[11] Stepinac, M.P., Lourenço, B., Atalić, J., Kišiček, T., Uroš, M., Baniček, M. \& Šavor Novak, M., Damage classification of residential buildings in the historical downtown after the ML5.5 earthquake in Zagreb, Croatia in 2020. International Journal of Disaster Risk Reduction, 56, pp. 1-20, 2021. DOI: 10.1016/j.ijdrr.2021.102140.

[12] Mujeri, M.K. \& Mujeri, N., Unexpected challenges: COVID-19 and Cyclone Amphan. Structural Transformation of Bangladesh Economy, pp. 249-273, 2021.

[13] Srivastava, S., Protecting the most vulnerable amidst COVID-19 and Cyclone Amphan, 27 May, 2020.

[14] United Nations Women, As Bangladesh battles COVID-19 and the aftermath of Suer Cyclone Amphan, Women's organizations lead their communities through recovery, June 15, 2020. 
[15] Ishiwatari, M., Koike, T., Hiroki, K., Toda, T. \& Katsube, T., Managing disasters amid COVID-19 pandemic: Approaches for response to flood disasters. Progress in Disaster Science, 6, pp. 1-4, 2020. DOI: 10/1016/j.pdisas.2020.100096.

[16] Shultz, J.M., Fugate, C. \& Galea, S., Cascading risks of COVID-19 resurgence during an active 2020 Atlantic hurricane season. Journal of American Medical Association, 324(10), pp. 935-936, 2020. DOI: 10.1001/jama.2020.15398.

[17] Meyers, T., Multiple disasters strain response systems, slow recovery, and deepen inequity. Direct Relief, 7 Oct. 2020.

[18] Tracey, M.R., Plemmons, A. \& Belasen, A.R., Throwing caution to the wind: COVID19 and hurricanes, pp. 1-8, 2021.

[19] National Weather Service, Hurricane Laura.

[20] Miller, R.W., Hughes, T., Jervis, R. \& Rice, D., Hurricane Laura live coverage: Trump to visit damaged areas; At least 6 dead after 'extensive' damage to Louisiana. USA Today, 1 Sep., 2020.

[21] Hiller, J. \& Hampton, L., Pandemic stresses massive Hurricane Laura evacuations in Texas, Louisiana. Reuters, 26 Aug., 2020.

[22] McCullough, J. \& Garnham, J.P., As Hurricane Laura heads for Southeast Texas, officials scramble to evacuate and shelter people during a pandemic. The Texas Tribune, 26 Aug., 2020.

[23] Doss-Gollin, J., Franham, D.J., Lall, U. \& Modi, V., How unprecedented was the February 2021 Texas cold snap. Environmental Research Letters, 16, pp. 1-7, 2021. DOI: $10.1088 / 1748-9326 / \mathrm{ac} 0278$.

[24] Busby, J.W. et al., Cascading risks: Understanding 2021 winter blackout in Texas. Energy Research and Social Science, 77, pp. 1-10. DOI: 10.1016/j.erss.2021.102106.

[25] Courtney, B., Toner, E., Waldhorn, A., Franco, C., Rambhia, K., Norwood, A., Inglesby, T.V. \& O'Toole, T., Healthcare coalitions: The new foundation for national healthcare preparedness and response for catastrophic health emergencies. Biosecurity and Bioterrorism, 7(2), pp. 153-163, 2009. DOI: 10.1089/bsp.2009.0020.

[26] US Department of Health and Human Services, Public health emergency: Public health and emergency medical support for nation prepared. https://www.phe.gov/ Preparedness/planning/hpp/reports/pmi-guidance-2019-2023/Pages/

Background.aspx. Accessed on: 10 Jun. 2021.

[27] National Association of County and City Health Officials, Statement of policy, healthcare coalition structure, pp. 1-6, 2021.

[28] Hathaway, W. \& Meyer, D.S., Competition and cooperation in social movement coalitions: Lobbying for peace in the 1980s. Berkeley Journal of Sociology, 38, pp. 157-183, 1993.

[29] Murphy, G., Coalitions and the development of the global environmental movement: A double-edged sword. Mobilization, 10, pp. 235-250, 2005.

DOI: $10.17813 /$ maiq.10.2.8u3626408607643t.

[30] Aldrich, D.P. \& Meyer, M.A., Social capital and community resilience. American Behavioral Scientist, 59, pp. 254-269, 2015. DOI: 10.1177/0002764214550299.

[31] Safdar, N., Abbo, L.M., Knobloch, M.J. \& Seo, S.K., Research methods in healthcare epidemiology: Survey and qualitative research. Infection Control Hospital Epidemiology, 37(11), pp. 1272-1277, 2016.

[32] Mays, N. \& Pope, C., Assessing quality in qualitative research. BMJ, 320, pp. 50-52, 2000 . 
[33] Felice, C., Luca Di Tanna, G., Zanus, G. \& Grossi, U., Impact of COVID-19 outbreak on healthcare workers in Italy; Results from a national e-survey. Journal of Community Health, 45, pp. 675-683, 2020. DOI: 10.1007/s10900-020-00845-5.

[34] Centers for Medicare and Medicaid Services (CMS), Emergency preparedness requirements by provider type. www.cms.gov/Medicare/Provider-Enrollment-andCertification/SurveyCertEmergPrep/Downloads/EP-Rule-Table-Provider-Type.pdf. Accessed on: 5 Jun. 2021.

[35] Provalis Research, QDA Miner, Computer software, Version 5.0.5, Montreal, 2017.

[36] Berelson, B., Content Analysis in Communication Research, The Free Press: New York, 1952.

[37] Krippendorff, K., Content Analysis: An Introduction to its Methodology, SAGE: London, 1980.

[38] Denham, M.A. \& Khemka, A.K., Homeland Security and emergency management in institutions of higher education (IHE): Texas case study. International Journal of Safety and Security Engineering, 7(3), pp. 1-15, 2017. DOI: $10.2495 /$ SAFE-V7-N3-337-351.

[39] Clavel, N. \& Pomey, M.-P., Enhancing patient involvement in quality improvement: How complaint managers see their roles and limitations. Patient Experience Journal, 7(3), pp. 112-118, 2020. DOI: 10.35680/2372-0247.1460.

[40] Pomey, M.-P. et al, The patient advisor, an organizational resource as a lever for an enhanced oncology patient experience (PAROLE-onco): A longitudinal multiple case study protocol. BMC Heath Services Research, pp. 1-12, 2021. DOI: 10.1186/s12913-020-06009-4.

[41] Hafling, D., Role of regional health care coalitions in managing and coordinating disaster response, 2013, NCBI, White Paper.

[42] Warren, M.R, Thompson, P.J. \& Saegert, S., The role of social capital in combating poverty. Social Capital and Poor Communities, eds S. Saegert, J.P. Thompson \& M.R. Warren, Russell Sage: New York, pp. 1-28, 2001.

[43] Pierce, J.R. Jr, Morley, S.K., West, T.A., Pentecost, P., Upton, L.A. \& Banks, L., Improving long-term care facility disaster preparedness and response: A literature review. Disaster Medicine and Public Health Preparedness, 11(1), pp. 140-149, 2016. DOI: 10/1017/dmp.2016.59.

[44] Trautsamwieser, A., Gronalt, M. \& Hirsch, P., Securing home health care in times of natural disasters, OR Spectrum, 33, pp. 787-813, 2011.

DOI: $10.1007 / \mathrm{s} 00291-011-0253-4$. 